\title{
Analitical study for the most using punches in men's world championship 2013 in boxing
}

\author{
Researcher / Mohamed Awad Ebrahim \\ Problem and introduction :
}

Boxing sport is characterized in recent times by rapid development as a result of the progress of plans and modern methods of play, which requires the development of training methods and methods in order to face this progress and scientific development in the field of training, which made the most important duties of coaches is to recognize the offensive and defensive punching skills on the vicious places aiming to improve the physical and tactical level of the player To achieve the best results.

Ehab Ezzat Abdel-Latif (2003) states that boxing is one of the downward activities in which a boxer alone can withstand competitive positions as he competes with his opponent in a limited space, which is the boxing ring, and he chooses from offensive skills models and competitive plans that he mastered during training in a way that is compatible with The position that is achieved on the ring also depends on the element of time from the beginning of the offensive punch from his opponent to his defense and then choosing the appropriate offensive punches to carry out the counter-attack.

Hussam Refky (1993) explains that boxing is one of the sports of battles in which two players of the same weight compete with each other using a fist in a series of specified time rounds. This is called winning a knockout or in the event that the opponent is injured to a degree that does not enable him to continue playing, which is called a technical knockout and in the event that neither of the two things occurs before the end of the estimated number of rounds, the winner is determined by either the decision of the referee or the number of points recorded by the registration judges. (2:15)

Mohamed Abdel Aziz (1995) notes that the nature of performance in boxing and the proximity of boxers to each other to the point of fusion at times, and the small area of the ring, and defining its aspects with ropes, gives its practitioners special physical 
characteristics, in addition to the factors of anxiety and tension associated with competition and sports in general. (7:23) Mohamed Abdel Aziz (1995) adds that boxing as an Olympic sport plays a prominent role in refining the souls of young and old as it allows them to participate in a highlevel competitive sport that brings them physical and health benefits in terms of being an individual sport that requires high-level preparation and ongoing training in addition to its practitioners. The greatest need towards maintaining health, Boxing is also one of the best sporting activities for energy depletion. I have conducted many studies and research and have found that boxing practitioners deplete energy during boxing and may make them more calm and social with the community. Boxing also contributes to the good social relations between players each other and between players, coaches and officials About them in clubs and federations. (7:23)

Through the expertise of the researcher and access to many research and scientific studies and follow-up to many international and Olympic courses, the latest of which is the 2013 World Championship for Men held in the State of Qatar in Doha, the researcher noted that punching groups, defenses and counterattack on the ring have the highest importance in achieving victory for boxers who are able to optimize the use of their capabilities and plans Toys that enable them to choose the appropriate competitive positions that suit their physical and technical potential The researcher also noted that many Egyptian coaches do not pay attention to punching and counterattacking groups while they are in the process of training and education for boxers, especially in the early years of age and this is consistent with many studies and research that indicated a low level of offensive and defensive punches and counterattack and punching groups on the ring with boxers Egyptians for their relatives are players in different punching schools, as there are no vocabulary in educational and training programs.

Research objective: 
Identify the most used punches in the three rounds of the 2013 World Men's

Championship in boxing.

Search questions:

What are the most used punches in the first round of boxers at the 2013

World Men's Championship? What are the most used punches in the second round of boxers at the 2013 World Men's Championship? What are the most used punches in the third round of boxers in the 2013 World Men's

Championship? What are the most used punches in the total of three rounds of boxers in the 2013 World Men's Championship?

\section{Prior studies :}

\section{$1^{\text {st }}$ study Mohsen Ramadan Ali (1990)(6)}

Study title: Defenses and their relationship to the results of matches in boxing. The aim of the study: to identify the most used types of defenses. Study method: The researcher used the descriptive approach. The study sample: consisting of (24) boxers participating in the Republic Championship in the first class. Study results: The most commonly used types of defenses are two legs.

The second study:

a study by Mohamed Abdel Aziz Ghonaim and Atef Maghawry (1991) (8) Study Title: An analytical study of some of the defensive plans used by the National Team boxers. The aim of the study: To identify the most used types of defensive line used by the Egyptian national team boxers, as well as the effectiveness of each. Study methodology: The two researchers used the descriptive approach. Study sample: The national team reached (36) boxers. The results of the study: that the most used types of defensive plans used to push the punch, block it and block it for the arms and use the transmission rings at the feet and tilt the trunk to the sides and back.

The third study: Study of Sedky Nour El-Din Mohamed, Dia El-Din El-Azab (1993) (4)

Study title: An analytical study of the results of the Egyptian boxers in the Fifth African Games. 
Objective of the study: The study aims to assess the level of the Egyptian team participating in the Fifth African Championship held in Cairo 1991, in order to compare it with the countries that won first place.

Study method: descriptive approach.

Study Sample: Analyzing the results of matches of (54) boxers, of whom (48) are boxers, and (6) Egyptians have not achieved any positions.

Study results: Decline in the level of technical performance of the Egyptian boxers by comparing them with the boxers who won the medals in the championship, as well as the low level of punches affecting the Egyptian team.

The fourth study: Study of Sedky Nour El-Din Mohamed, Dia El-Din El-Azab (1998) (5). Study title: An analytical study of the results of punching schools in the Olympic Games in Atlanta (1996). The aim of the study: to identify the type of punching school to which the boxers participating in the Olympic Games in Atlanta belong to, as well as to get acquainted with the results of the boxers of different punching schools (Cuban - American - European -

Russian) in the stand-by, punching distances, deception skills, offensive skills, counter attacking skills and defensive skills and a better identification School to you

\section{Secondly : Foreign studies :}

First study: Christopher Cheristopher (1997) (9). Study title: An analytical study of boxing match using contrast analysis (logistic). The aim of the study: to predict the boxing match through the development of a (logistic) model. Study method: The researcher used the descriptive method. Study Sample: (300) questionnaire for coaches, referees and players, to explore the factors affecting the results of boxing matches. The researcher also used the registration form as a means and tools for data collection. The results of the study: The researcher reached it will help in choosing the right direction for the analysis model. In the end, you can come out by identifying the match and estimating the gain or loss of the match.

Usefulness of related studies:

- The researcher believes that these studies as a whole have contributed to shedding light on defining the important foundations for this study, such as:

- Know how to analyze matches.

- Formulating goals and assumptions.

- - Knowledge of offensive behavior, defenses and counter-attack skills. 
- - Determining the appropriate curriculum for the nature of the current study.

- - Determining the sample, its method of selection and size.

- - Determining the most appropriate statistical treatments in proportion to the nature of this research.

- - Take advantage of how to discuss the results of previous studies in discussing the results of the current research.

Search procedures : Research Methodology : The researcher used the descriptive method in the survey method, as the researcher analyzed the 2013 men's world championship in boxing The research sample : The researcher analyzed the 2013 World Boxing Championship for men in boxing, and the research sample included 75 games in the final and final rounds of all weights for boxers. Research fields The human sphere: The 2013 World Boxing Championship for men in boxing. Time domain: From 5/31/2019 to 11/15/2019 Spatial domain: 2013 Men's World Championships in boxing.

The following table $(1,2)$ shows the number of matches and the countries participating in the championship in the final rounds 
Table no.1

\begin{tabular}{|c|c|c|c|c|}
\hline $\mathrm{S}$ & \multicolumn{2}{|c|}{ Description } & $\mathrm{NO}$ & Percentage of research sample \\
\hline 1 & \multicolumn{2}{|c|}{ Matches Analyzing } & 47 & $62.7 \%$ \\
\hline 2 & \multirow{2}{*}{$\begin{array}{l}\text { Excluded } \\
\text { Matches }\end{array}$} & $\begin{array}{c}\text { Final Blow } \\
\text { End }\end{array}$ & 3 & $4.0 \%$ \\
\hline 3 & & $\begin{array}{l}\text { Unclear } \\
\text { Filming }\end{array}$ & 25 & $33.3 \%$ \\
\hline 4 & \multicolumn{2}{|c|}{ Research Sample } & 75 & $100 \%$ \\
\hline
\end{tabular}

It is clear from Table (1) for the proportional representation of the research sample. The total of the research sample reached 75 matches, 47 of which are analytical games, and 28 matches are excluded, including three matches that ended with the judge and 25 . The photography match is unclear. 


\begin{tabular}{|c|c|c|c|c|}
\hline \multicolumn{2}{|c|}{ Statistical Significances } & Repetition & Percentage & $\begin{array}{l}\text { Total } \\
\text { Percentage }\end{array}$ \\
\hline 1 & ALG & 1 & 1.1 & 1.1 \\
\hline 2 & AZE & 9 & 9.6 & 10.6 \\
\hline 3 & BLR & 3 & 3.2 & 13.8 \\
\hline 4 & BRA & 3 & 3.2 & 17.0 \\
\hline 5 & $\mathrm{CHN}$ & 3 & 3.2 & 20.2 \\
\hline 6 & CRC & 1 & 1.1 & 21.3 \\
\hline 7 & $\mathrm{CRO}$ & 2 & 2.1 & 23.4 \\
\hline 8 & CUB & 17 & 18.1 & 41.5 \\
\hline 9 & EGY & 2 & 2.1 & 43.6 \\
\hline 10 & FRA & 4 & 4.3 & 47.9 \\
\hline 11 & GBR & 4 & 4.3 & 52.1 \\
\hline 12 & IND & 2 & 2.1 & 54.3 \\
\hline 13 & IRL & 9 & 9.6 & 63.8 \\
\hline 14 & KAZ & 5 & 5.3 & 69.1 \\
\hline 15 & LTU & 1 & 1.1 & 70.2 \\
\hline 16 & MAR & 3 & 3.2 & 73.4 \\
\hline 17 & NED & 1 & 1.1 & 74.5 \\
\hline 18 & PHI & 1 & 1.1 & 75.5 \\
\hline 19 & RUS & 8 & 8.5 & 84.0 \\
\hline 20 & THA & 1 & 1.1 & 85.1 \\
\hline 21 & TUR & 1 & 1.1 & 86.2 \\
\hline 22 & UKR & 3 & 3.2 & 89.4 \\
\hline 23 & UZB & 10 & 10.6 & 100.0 \\
\hline Total & & 94 & 100.0 & \\
\hline
\end{tabular}

It is clear from Table (2) of the significance and frequency and percentage of matches according to the country in which the matches are in discussion, the highest frequency of repetition of the CUB state came with 17 matches with $18.1 \%$, UZB with 10 games with $10.6 \%$, and AZE, IRL with 9 games with $9.6 \%$, And Russia's RUS state with 8 games, $8.5 \%$, and the lowest country in which to play matches in the final and semifinal rounds (TUR, THA, PHI, LTU, CRC) came in at $1.1 \%$. Table $(3,4,5$, and 6) shows the statistical significance of the search variables for the match in the three rounds, and a total of 3 rounds of the matches under discussion are attached (2)

Tools and devices used in the research: 
1- Arab and foreign sources.

2- The objective observation.

- Stopwatch number (1).

- Projector Analysis forms Evaluation Forms - PC

Steps to implement the search:

The researcher has taken the following steps:

1- The researcher used an observation form designed by the researcher. Attachment

2-On the basis of this form, the researcher department analyzes the matches according to the skills of individual straight punches, individual hooks punches, individual upward punches, marital punches, total punches, defenses, and counter-attack for each of the three rounds in the game.

4- The researcher relied on the scientific principles to codify the analysis form, as he presented the form to some experts and specialists

Basic study:

The researcher analyzed the World Boxing Championships 2015 in Qatar in Doha, and the research sample included 75 games in the final and final rounds of all weights for boxers in the form that was designed for this purpose.

Statistical treatments used:

The researcher used the following statistical treatments: "

- Statistical program spss Repetition and percentage.

- Relative importance . Correlation coefficient.

- T test.

First: Present the results 
Repetition and percentage between winning and losing players in the matches:

Table (7) Repetition and percentage of search variables for the match for the player (the winner. The loser) in the first round, $n=47$ games.

\begin{tabular}{|c|c|c|c|c|c|}
\hline \multirow{2}{*}{$\begin{array}{c}\text { Statistical } \\
\text { Significances }\end{array}$} & \multicolumn{2}{|c|}{ Winner } & \multicolumn{2}{c|}{ Loser } \\
\cline { 2 - 5 } \\
\cline { 2 - 5 } & Repetition & Percentage & Repetition & Percentage & \\
\hline $\begin{array}{c}\text { Individually } \\
\text { Straight }\end{array}$ & 417 & $53.32 \%$ & 365 & $46.68 \%$ & 782 \\
\hline Individually Hook & 107 & $54.87 \%$ & 88 & $45.13 \%$ & 195 \\
\hline Individually Rising & 50 & $57.47 \%$ & 37 & $42.53 \%$ & 87 \\
\hline Marital Punches & 393 & $51.31 \%$ & 373 & $48.69 \%$ & 766 \\
\hline Total Punches & 243 & $50.31 \%$ & 240 & $49.69 \%$ & 483 \\
\hline Defense & 281 & $50.54 \%$ & 275 & $49.46 \%$ & 556 \\
\hline Counterattack & 246 & $63.90 \%$ & 139 & $36.10 \%$ & 385 \\
\hline
\end{tabular}

It is clear from Table (7), which is the frequency and percentage of search variables for the match for the player (the winner. The loser) In the first round, the highest percentage of offensive and defensive behavior and counter-attack for the winners of the counter-attack came in at a rate of $63.90 \%$, followed by ascending individual punches by $57.47 \%$, while it came The highest percentage of losers in offensive and defensive behavior and counterattacking of the punching group is $49.69 \%$, and defenses are $49.46 \%$. 
Table (8) Repetition and percentage of search variables for the match for the player (the winner. The loser) in the second round, $n=47$ games.

\begin{tabular}{|c|c|c|c|c|c|}
\hline $\begin{array}{r}\text { Statistical } \\
\text { Significances }\end{array}$ & \multicolumn{2}{c|}{ Winner } & \multicolumn{2}{c|}{ Toser } & \\
\cline { 2 - 5 } Variables & Repetition & Percentage & Repetition & Percentage & \\
\hline $\begin{array}{c}\text { Individually } \\
\text { Straight }\end{array}$ & 372 & $56.19 \%$ & 290 & $43.81 \%$ & 662 \\
\hline Individually Hook & 80 & $52.63 \%$ & 72 & $47.37 \%$ & 152 \\
\hline Individually Rising & 17 & $45.95 \%$ & 20 & $54.05 \%$ & 37 \\
\hline Marital Punches & 371 & $54.56 \%$ & 309 & $45.44 \%$ & 680 \\
\hline Total Punches & 272 & $57.14 \%$ & 204 & $42.86 \%$ & 476 \\
\hline Defense & 180 & $50.00 \%$ & 180 & $50.00 \%$ & 360 \\
\hline Counterattack & 186 & $64.14 \%$ & 104 & $35.86 \%$ & 290 \\
\hline
\end{tabular}

It is clear from Table (8) that the recurrence and percentage of search variables for the match for the player (the winner. The loser) In the second round, the highest percentage of offensive and defensive behavior and counter-attack came to the winners of the counter-attack at a rate of $64.14 \%$, followed by punching groups by 2014\%, while higher The percentage of players losers in offensive and defensive behavior and counter-attack of individual bullets is $54.05 \%$, and defenses are $50.00 \%$ 
Table (9) Repetition and percentage\% of search variables for the match for the player (the winner. The loser) in the third round, $\mathrm{n}=47$ games.

\begin{tabular}{|c|c|c|c|c|c|}
\hline \multirow{2}{*}{$\begin{array}{c}\text { Statistical } \\
\text { Significances }\end{array}$} & \multicolumn{2}{c|}{ Winner } & \multicolumn{2}{c|}{ Loser } & \\
\cline { 2 - 5 } Variables & Repetition & Percentage & Repetition & Percentage & \\
\hline $\begin{array}{c}\text { Individually } \\
\text { Straight }\end{array}$ & 407 & $58.06 \%$ & 294 & $41.94 \%$ & 701 \\
\hline Individually Hook & 94 & $52.51 \%$ & 85 & $47.49 \%$ & 179 \\
\hline Individually Rising & 28 & $54.90 \%$ & 23 & $45.10 \%$ & 51 \\
\hline Marital Punches & 369 & $53.79 \%$ & 317 & $46.21 \%$ & 686 \\
\hline Total Punches & 217 & $50.82 \%$ & 210 & $49.18 \%$ & 427 \\
\hline Defense & 206 & $47.69 \%$ & 226 & $52.31 \%$ & 432 \\
\hline Counterattack & 171 & $59.58 \%$ & 116 & $40.42 \%$ & 287 \\
\hline
\end{tabular}

It is clear from Table (9) that the repetition and the percentage of search variables for the match for the player (the winner. The loser) In the third round, the highest percentage of offensive and defensive behavior and counterattack of the winners of the counterattack came in at a rate of $59.58 \%$, followed by individual punches in the straight rate of $58.06 \%$, while it came The highest percentage of players losers in offensive, defensive and anti-defensive behavior was $52.31 \%$, and punching groups were $49.18 \%$ 
Table (10) Repetition and percentage of search variables for the match for the player (the winner. The loser) in a total of 3 rounds $\mathrm{N}=47$ games.

\begin{tabular}{|c|c|c|c|c|c|}
\hline \multirow{2}{*}{$\begin{array}{c}\text { Statistical } \\
\text { Significances }\end{array}$} & \multicolumn{2}{|c|}{ Winner } & \multicolumn{2}{c|}{ Loser } & \\
\cline { 2 - 5 } Variables & Repetition & Percentage & Repetition & Percentage & \\
\hline $\begin{array}{c}\text { Individually } \\
\text { Straight }\end{array}$ & 1196 & $55.76 \%$ & 949 & $44.24 \%$ & 2145 \\
\hline Individually Hook & 281 & $53.42 \%$ & 245 & $46.58 \%$ & 526 \\
\hline Individually Rising & 95 & $54.29 \%$ & 80 & $45.71 \%$ & 175 \\
\hline Marital Punches & 1133 & $53.14 \%$ & 999 & $46.86 \%$ & 2132 \\
\hline Total Punches & 732 & $52.81 \%$ & 654 & $47.19 \%$ & 1386 \\
\hline Defense & 667 & $49.48 \%$ & 681 & $50.52 \%$ & 1348 \\
\hline Counterattack & 603 & $62.68 \%$ & 359 & $37.32 \%$ & 962 \\
\hline
\end{tabular}

It is clear from Table (10) that the frequency and percentage of search variables for the match for the player (the winner. The loser) in the total of 3 rounds is highest. The highest percentage of losers came in offensive and defensive behavior and antidefensive attack by $50.52 \%$, and punching groups by $47.19 \%$. 
Show results of comparison between search variables for winning players and losers in the games under discussion

Table (11) Statistical significance between search variables for winning players and losers in the first round

\begin{tabular}{|c|c|c|c|c|c|c|c|}
\hline \multirow{2}{*}{$\begin{array}{r}\text { Statistical } \\
\text { Significances }\end{array}$} & \multicolumn{2}{|c|}{$\begin{array}{c}\text { Winner Players } \\
n=47\end{array}$} & \multicolumn{2}{|c|}{$\begin{array}{l}\text { Loser Players } \\
\qquad \mathrm{n}=47\end{array}$} & \multirow{2}{*}{$\begin{array}{l}\text { Difference } \\
\text { Between } \\
\text { Two } \\
\text { Averages }\end{array}$} & \multirow[t]{2}{*}{$\begin{array}{l}\text { Value of } \\
\text { (T) }\end{array}$} & \multirow[t]{2}{*}{$\begin{array}{c}\text { Significance } \\
\text { Level }\end{array}$} \\
\hline & $\mathrm{X}$ & $\mathrm{Y} \pm$ & $\mathrm{X}$ & $\mathrm{Y} \pm$ & & & \\
\hline $\begin{array}{l}\text { Individually } \\
\text { Straight }\end{array}$ & 8.87 & 2.63 & 7.64 & 2.44 & 1.23 & $2.36^{*}$ & 0.02 \\
\hline $\begin{array}{l}\text { Individually } \\
\text { Hook }\end{array}$ & 2.32 & 1.00 & 1.85 & 0.91 & 0.47 & $2.37 *$ & 0.02 \\
\hline $\begin{array}{c}\text { Individually } \\
\text { Rising }\end{array}$ & 1.09 & 0.72 & 0.74 & 0.71 & 0.34 & $2.32 *$ & 0.02 \\
\hline Marital Punches & 8.32 & 2.11 & 7.94 & 2.67 & 0.38 & 0.77 & 0.44 \\
\hline Total Punches & 5.32 & 2.41 & 4.98 & 2.10 & 0.34 & 0.73 & 0.47 \\
\hline Defense & 6.21 & 3.13 & 5.64 & 2.09 & 0.57 & 1.05 & 0.30 \\
\hline Counterattack & 5.26 & 2.04 & 2.85 & 2.08 & 2.40 & $5.65 *$ & 0.00 \\
\hline
\end{tabular}

From the table (11) on the statistical significance between the search variables for the winning players and the losing players in the first round, it is clear that there are statistically significant differences at the level (0.05) between the winning and losing players in favor of the winning players in the punches (straight individual, hook, individual, upward, attack Counter)) where the calculated value of (T) was greater than the tabular value of $(\mathrm{T})$ at $(0.05)=(1.98)$ and at a level of significance less than 0.05. While there are no statistically significant differences in other offensive and defensive skills. 
Table (12) Statistical significance between the search variables for winning and losing players in the second round

\begin{tabular}{|c|c|c|c|c|c|c|c|}
\hline \multirow{2}{*}{$\begin{array}{r}\text { Statistical } \\
\text { Significances } \\
\text { Variables }\end{array}$} & \multicolumn{2}{|c|}{$\begin{array}{c}\text { Winner Players } \\
n=47\end{array}$} & \multicolumn{2}{|c|}{$\begin{array}{c}\text { Loser Players } \\
n=47\end{array}$} & \multirow{2}{*}{$\begin{array}{l}\text { Difference } \\
\text { Between } \\
\text { Two } \\
\text { Averages }\end{array}$} & \multirow[t]{2}{*}{$\begin{array}{l}\text { Value of } \\
\text { (T) }\end{array}$} & \multirow[t]{2}{*}{$\begin{array}{c}\text { Significance } \\
\text { Level }\end{array}$} \\
\hline & $\mathrm{X}$ & $\mathrm{Y} \pm$ & $\mathrm{X}$ & $\mathrm{Y} \pm$ & & & \\
\hline $\begin{array}{l}\text { Individually } \\
\text { Straight }\end{array}$ & 7.91 & 1.93 & 6.17 & 2.15 & 1.74 & $4.14 *$ & 0.00 \\
\hline $\begin{array}{c}\text { Individually } \\
\text { Hook }\end{array}$ & 1.72 & 1.17 & 1.49 & 1.00 & 0.23 & 1.04 & 0.30 \\
\hline $\begin{array}{l}\text { Individually } \\
\text { Rising }\end{array}$ & 0.36 & 0.61 & 0.45 & 0.65 & -0.09 & 0.66 & 0.51 \\
\hline $\begin{array}{l}\text { Marital } \\
\text { Punches }\end{array}$ & 7.91 & 1.43 & 6.53 & 2.11 & 1.38 & $3.72 *$ & 0.00 \\
\hline Total Punches & 5.83 & 2.42 & 4.23 & 2.13 & 1.60 & $3.40^{*}$ & 0.00 \\
\hline Defense & 3.98 & 1.99 & 3.70 & 1.94 & 0.28 & 0.68 & 0.50 \\
\hline Counterattack & 4.00 & 2.07 & 2.09 & 1.98 & 1.91 & $4.58 *$ & 0.00 \\
\hline
\end{tabular}

It is clear from Table (12) of the statistical significance between the search variables for the winning players and the losing players in the second round: There are statistically significant differences at the level (0.05) between the winning and losing players in favor of the winning players in (individual straight punches, marital punches, total punches, attack Counterattack), where the calculated value of (T) was greater than the tabular value of $(\mathrm{T})$ at $(0.05)=(1.98)$ and at a level of significance less than 0.05 , while there were no statistically significant differences in the rest of the offensive and defensive skills. 
Table (13) Statistical significance between the search variables for winning and losing players in the third round

\begin{tabular}{|c|c|c|c|c|c|c|c|}
\hline \multirow{2}{*}{$\begin{array}{r}\begin{array}{r}\text { Statistical } \\
\text { Significances }\end{array} \\
\text { Variables }\end{array}$} & \multicolumn{2}{|c|}{$\begin{array}{c}\text { Winner Players } \\
Z=47\end{array}$} & \multicolumn{2}{|c|}{$\begin{array}{l}\text { Loser Players } \\
\qquad Z=47\end{array}$} & \multirow{2}{*}{$\begin{array}{c}\text { Difference } \\
\text { Between } \\
\text { Two } \\
\text { Averages }\end{array}$} & \multirow[t]{2}{*}{$\begin{array}{l}\text { Value of } \\
\text { (T) }\end{array}$} & \multirow[t]{2}{*}{$\begin{array}{c}\text { Significance } \\
\text { Level }\end{array}$} \\
\hline & $\mathrm{X}$ & $\mathrm{Y} \pm$ & $\mathrm{X}$ & $\mathrm{Y} \pm$ & & & \\
\hline $\begin{array}{l}\text { Individually } \\
\text { Straight }\end{array}$ & 8.70 & 2.47 & 6.15 & 2.71 & 2.55 & $4.78 *$ & 0.00 \\
\hline $\begin{array}{c}\text { Individually } \\
\text { Hook }\end{array}$ & 2.02 & 0.94 & 1.79 & 0.91 & 0.23 & 1.23 & 0.22 \\
\hline $\begin{array}{l}\text { Individually } \\
\text { Rising }\end{array}$ & 0.62 & 0.61 & 0.49 & 0.66 & 0.13 & 0.98 & 0.33 \\
\hline Marital Punches & 7.87 & 1.94 & 6.72 & 2.37 & 1.15 & $2.57 *$ & 0.01 \\
\hline Total Punches & 4.74 & 1.95 & 4.34 & 2.21 & 0.40 & 0.94 & 0.35 \\
\hline Defense & 4.55 & 2.76 & 4.66 & 2.32 & -0.11 & 0.20 & 0.84 \\
\hline Counterattack & 3.70 & 1.80 & 2.36 & 1.82 & 1.34 & $3.58 *$ & 0.00 \\
\hline
\end{tabular}

From the table (13) on the statistical significance between the search variables for the winning players and the losing players in the third round, it is clear that there are statistically significant differences at the level (0.05) between the winning and losing players in favor of the winning players in (straight individual punches, marital punches, counterattack) where The calculated value of (T) was greater than the tabular value of $(\mathrm{T})$ at the level of $(0.05)=(1.98)$ and at a level of significance less than 0.05 , while there were no statistically significant differences in the rest of the offensive and defensive skills. 
Table (14) Statistical indications between search variables for winning players and losers in a total of three rounds

\begin{tabular}{|c|c|c|c|c|c|c|c|}
\hline \multirow{2}{*}{$\begin{array}{r}\text { Statistical } \\
\text { Significances }\end{array}$} & \multicolumn{2}{|c|}{$\begin{array}{c}\text { Winner Players } \\
\mathrm{Z}=47\end{array}$} & \multicolumn{2}{|c|}{$\begin{array}{c}\text { Loser Players } \\
Z=47\end{array}$} & \multirow{2}{*}{$\begin{array}{l}\text { Difference } \\
\text { Between } \\
\text { Two } \\
\text { Averages }\end{array}$} & \multirow[t]{2}{*}{$\begin{array}{l}\text { Value of } \\
\text { (T) }\end{array}$} & \multirow[t]{2}{*}{$\begin{array}{c}\text { Significance } \\
\text { Level }\end{array}$} \\
\hline & $X$ & $\mathrm{Y} \pm$ & $X$ & $\mathrm{Y} \pm$ & & & \\
\hline $\begin{array}{c}\text { Individually } \\
\text { Straight }\end{array}$ & 25.45 & 5.97 & 20.19 & 6.63 & 5.26 & $4.04 *$ & 0.00 \\
\hline $\begin{array}{c}\text { Individually } \\
\text { Hook }\end{array}$ & 5.98 & 2.23 & 5.21 & 2.05 & 0.77 & 1.73 & 0.09 \\
\hline $\begin{array}{l}\text { Individually } \\
\text { Rising }\end{array}$ & 2.02 & 0.94 & 1.70 & 1.16 & 0.32 & 1.46 & 0.15 \\
\hline $\begin{array}{c}\text { Marital } \\
\text { Punches }\end{array}$ & 24.11 & 4.29 & 21.26 & 6.18 & 2.85 & $2.60 *$ & 0.01 \\
\hline Total Punches & 15.57 & 5.83 & 13.91 & 5.62 & 1.66 & 1.40 & 0.16 \\
\hline Defense & 14.19 & 6.45 & 14.49 & 6.25 & -0.30 & -0.23 & 0.82 \\
\hline Counterattack & 12.83 & 5.11 & 7.64 & 5.55 & 5.19 & $4.71 *$ & 0.00 \\
\hline
\end{tabular}

It is clear from Table (14) of the statistical significance between the search variables for the winning players and the losing players in the total of three rounds: There are statistically significant differences at the level (0.05) between the winning and losing players in favor of the winning players in (straight individual punches, marital punches, counterattack) Where the calculated value of $(\mathrm{T})$ was greater than the tabular value of $(\mathrm{T})$ at the level of $(0.05)=(1.98)$ and at a level of significance less than 0.05 , while there were no statistically significant differences in the rest of the offensive and defensive skills.

Second: Discussing the results.

It is clear from Table (7), which is the frequency and percentage of search variables for the match

For the player (winner. Loser) in the total matches under discussion in the first round, the highest percentage of counterattack came, followed by ascending individual punches, while the highest percentage of losers came in the punching group, followed by defenses. 
This is consistent with the results of the study of Sedky Nour El-Din Mohamed, Dia El-Din El-Azab (1998). Determining the distinguished performance of each school for you, as well as the superiority of the Cuban school, followed by the Russian, European, and American schools in total game play, and also the apparent lack of affiliation of Egyptian boxers to any of the punching schools with a weak level. Boxing technician (skilled and schematic). (5)

This is consistent with the results of the study of Sedky Nour El-Din Mohamed, Dia El-Din El-Azab (1993). The low level of technical performance of Egyptian boxers by comparing them with boxers who won medals in the championship, as well as the low level of punches affecting the Egyptian team. (4)

As shown in Table (8), the frequency and the percentage of search variables for the match for the player (the winner. The loser) in the total matches under discussion in the second round are higher, the highest percentage of players winning the counterattack followed by punching groups, while the highest percentage of players losing in the individual punches The ascending has distress and defenses.

As shown in Table (9), the frequency and the percentage of search variables for the match for the player (the winner. The loser) in the total matches under discussion in the third round are highest, the highest percentage of winning players in the counter attack followed by individual straight punches, while the highest percentage of players losing in Impellers followed by punching combinations

As shown in Table (10), the frequency and percentage of the search variables of the match for the player (the winner. The loser) in the total matches under discussion in the total of 3 rounds, the highest percentage of the winning players in the counter attack followed by the individual straight punches, while the highest percentage of the losing players came. In defenses, punching groups follow by. 
This researcher attributes this change between the search variables for the winning players and the losers in the games, because there are many developed countries in the field of boxing sports such as Cuba, the United States of America, Russia, Romania, Germany, Poland, Bulgaria and other countries. The importance of the rapid change in the modification of training methods (physical, skill and planning) to keep pace with this development, which is reflected in the speed of the punches in the head areas only. That is, an attempt to pay attention to the speed of the rating and the accuracy of the scoring instead of relying on strength to achieve a winning punches.

These results are consistent with the results of Sami Moheb's study, Nagy Ismail (2005) that the average number of punches in the final matches for the player who won first place (146) punches and the average number of punches for Egyptian players (85) and therefore there are differences between Egyptian boxers and firstplace holders At the Olympic Games in Athens. (3)

As shown in Table No. (11) concerning the statistical significance between the search variables for the winning players and the losing players in the matches under discussion in the first round: There are statistically significant differences between the winning and losing players in favor of the winning players in the punches (straight individual, hook, individual, upward individual, Counter attack) while there are no statistically significant differences in other offensive and defensive skills.

This is consistent with the results of the study of Sedky Nour El-Din Mohamed, Dia El-Din El-Azab (1993) that there is a decline in the technical performance level of Egyptian boxers by comparing them with boxers who won medals in the championship, as well as the low level of punches affecting the Egyptian team. (4) These results also coincide with the results of the study of Sami Moheb, Nagy Ismail (2005). The study concluded that the average number of punches in the final matches for the player who won first place (146) punches and the average number of punches for Egyptian players (85) and therefore there are differences between the boxers Egyptians and first-place holders at the Olympic Games in Athens. (3) 


\section{These results are also consistent with the results of the study of Christopher Cheristopher (1997) reached by the researcher. It will help in choosing the right direction for the analysis model. In the end, you can come up by defining the match and estimating the gain or loss of the match. (9)}

As shown in Table No. (12) concerning the statistical significance between the search variables for the winning players and the losing players in the matches under discussion in the second round: there are statistically significant differences between the winning and losing players in favor of the winning players in (individual straight punches, marital punches, total punches, Counter attack), while there are no statistically significant differences in other offensive and defensive skills.

This researcher attributes this change between the search variables for the winning players and the losers in the games, because there are many developed countries in the field of boxing sports such as Cuba, the United States of America, Russia, Romania, Germany, Poland, Bulgaria and other countries. The importance of the rapid change in the modification of training methods (physical, skill and planning) to keep pace with this development, which is reflected in the speed of punches in the head areas only. That is, an attempt to pay attention to the speed of the rating and the accuracy of the scoring instead of relying on strength to achieve a winning punches.

As shown in Table No. (13) concerning the statistical significance between the search variables for the winning players and the losing players in the matches under discussion in the third round: there are statistically significant differences between the 
winning and losing players in favor of the winning players in (straight individual punches, marital punches, counterattack) While there are no statistically significant differences in the rest of the offensive and defensive skills.

This researcher attributes this change between the search variables for the winning players and the losers in the games, because there are many developed countries in the field of boxing sports such as Cuba, the United States of America, Russia, Romania, Germany, Poland, Bulgaria and other countries. The importance of the rapid change in the modification of training methods (physical, skill and planning) to keep pace with this development, which is reflected in the speed of punches in the head areas only. That is, an attempt to pay attention to the speed of the rating and the accuracy of the scoring instead of relying on strength to achieve a winning punches.

This is consistent with the results of Sami Moheb's study, Nagy Ismail (2005) that the average number of punches in the final matches for the player who won first place (146) punches and the average number of punches for Egyptian players (85) and therefore there are differences between the Egyptian boxers and first-place holders in Athens Olympic Games. (3)

As shown in Table No. (14) concerning the statistical significance between the search variables for the winning players and the losing players in the matches under discussion in the match: there are statistically significant differences between the winning and losing players in favor of the winning players in (straight individual punches, marital punches, counterattack), While there are no statistically significant differences in other offensive and defensive skills.

This researcher attributes this change between the search variables for the winning players and the losers in the games, because there are many developed countries in the field of boxing sports such as Cuba, the United States of America, Russia, Romania, Germany, Poland, Bulgaria and other countries. The importance of the rapid change in the modification of training methods (physical, skill and planning) to keep pace with this development, which is reflected in the speed of punches in the head areas only. That is, an attempt to pay attention to the speed of the rating and the accuracy of the scoring instead of relying on strength to achieve a winning punches.

The results of this study are consistent with the results of Mohsen Ramadan's study on (1990) that the most used types of defenses are the two legs. (6)

First: Conclusions: - The highest percentage of winners came in the first round of counterattack with a rate of $63.90 \%$, followed by bullish individual punches by $57.47 \%$, while the highest percentage of losers came in a punching group with $49.69 \%$, and defenses at $49.46 \%$. - The highest percentage of winning players in the second round was also for the counterattack with a rate of 
$64.14 \%$, followed by punching groups by $12.5 \%$, while the highest percentage of players losing to players came in individual bulls by $54.05 \%$, and defenses by $50.00 \%$.

- The highest percentage of winners came in the third round of counterattack also with a rate of $59.58 \%$, followed by individual straight punches by $58.06 \%$, while the highest percentage of losers in defenses came by $52.31 \%$, and punching groups by $49.18 \%$. - The highest percentage of winning players in the total match came with a counter attack by $62.68 \%$, followed by individual straight punches by $55.76 \%$, while the highest percentage of losers in defenses came by $50.52 \%$, and punching groups by $47.19 \%$

- There were significant differences between winning and losing players in favor of winning players in the first round in punches (straight individual, hooky individual, ascending individual, counterattack) in favor of winning players, while there were no statistically significant differences in other offensive and defensive skills. - There were significant differences between winning and losing players in favor of the winning players in the second round in skills (straight individual punches, marital punches, total punching, counterattack), while there were no statistically significant differences in other offensive and defensive skills.

- There were significant differences between winning and losing players in favor of the winning players in the third round in skills (straight individual punches, marital punches, counterattack), while there were no statistically significant differences in other offensive and defensive skills. - There are significant differences between winning and losing players in favor of the winning players in the total match in skills (straight individual punches, marital punches, counterattack), while there are no statistically significant differences in other offensive and defensive skills.

Second: Recommendations

- Attention to training boxers to counter-attack according to the types of players.

- Work to train boxers on various punching groups throughout the preparation and pre-competition period.

- Paying attention to developing modern exercises with the latest training methods during training programs for boxing athletes.

- Learn about the methods and methods of attack, defense and international counterattack and how to benefit from them through training programs and competitions for boxers. 
resources

1. Cheristopher : Anempirical shudgn of boxing match predicition using alogistic regression analysis injung seongjeaih. When ghmon and telsohgoon, 1997. 